\title{
Assessing methanotrophy and carbon fixation for biofuel production by Methanosarcina acetivorans
}

Hadi Nazem-Bokaee1, Saratram Gopalakrishnan¹, James G. Ferry², Thomas K. Wood ${ }^{1,2}$ and Costas D. Maranas ${ }^{1 *}$

\begin{abstract}
Background: Methanosarcina acetivorans is a model archaeon with renewed interest due to its unique reversible methane production pathways. However, the mechanism and relevant pathways implicated in (co)utilizing novel carbon substrates in this organism are still not fully understood. This paper provides a comprehensive inventory of thermodynamically feasible routes for anaerobic methane oxidation, co-reactant utilization, and maximum carbon yields of major biofuel candidates by M. acetivorans.

Results: Here, an updated genome-scale metabolic model of M. acetivorans is introduced (iMAC868 containing 868 genes, 845 reactions, and 718 metabolites) by integrating information from two previously reconstructed metabolic models (i.e., iVS941 and iMB745), modifying 17 reactions, adding 24 new reactions, and revising 64 gene-proteinreaction associations based on newly available information. The new model establishes improved predictions of growth yields on native substrates and is capable of correctly predicting the knockout outcomes for 27 out of 28 gene deletion mutants. By tracing a bifurcated electron flow mechanism, the iMAC868 model predicts thermodynamically feasible (co)utilization pathway of methane and bicarbonate using various terminal electron acceptors through the reversal of the aceticlastic pathway.
\end{abstract}

Conclusions: This effort paves the way in informing the search for thermodynamically feasible ways of (co)utilizing novel carbon substrates in the domain Archaea.

Keywords: Methanosarcina acetivorans, Genome-scale metabolic model, Methane utilization

\section{Background}

Methane, the second most important greenhouse gas, is regulated primarily by microbial processes [1]. A renewed interest in methane as a gas substrate for the production of biofuels is spearheaded by its abundance in shale gas [2-5]. At the same time, concerns related with methane's role as a potent greenhouse gas drives the need to mitigate its adverse environmental impact [6]. Advances in the characterization of microbial consortia in anoxic sediments have revealed the potential of transforming methane into various products through biological routes [7-10].

\footnotetext{
*Correspondence: costas@psu.edu

1 Department of Chemical Engineering, The Pennsylvania State University, University Park, PA 16802, USA

Full list of author information is available at the end of the article
}

The global methane cycle is predominantly controlled by anaerobic methanotrophic archaea (ANME) in anoxic environments $[11,12]$ and aerobic methanotrophic bacteria at the anoxic-oxic interface of habitats $[13,14]$. Aerobic methanotrophy [15], proceeds via the oxidation of methane to methanol by a methane monooxygenase and then to formaldehyde by methanol dehydrogenase, which is subsequently integrated into central carbon metabolism through the ribulose monophosphate or the serine pathway [16]. This scheme, however, requires an initial activation cost in the form of $\operatorname{NAD}(\mathrm{P}) \mathrm{H}$, which is replenished at the expense of carbon efficiency. Shaped by the paucity of available energy, the anaerobic methanotrophy has been shown to exhibit better carbon and energy efficiency $[17,18]$. However, in contrast to the aerobic route, anaerobic methanotrophy is relatively 
poorly characterized as a result of the difficulties in culturing ANMEs in the lab [11] arising from syntrophy requirements. In such environments, the anaerobic methanotroph oxidizes methane and the microbial partner reduces an electron acceptor, often an inorganic ion such as $\mathrm{NO}_{3}{ }^{-}$[19] or $\mathrm{SO}_{4}{ }^{2-}$ [20]. Despite these difficulties, recent metagenomics analysis of ANMEs has partially revealed the methanotrophic pathways, observed in most methanogenic archaea, demonstrating the phylogenetic relationship between ANMEs and methanogens $[21,22]$. Of particular interest is the methanogenic archaeon Methanosarcina acetivorans for which trace methane oxidation has been observed [23, 24] implying that it possesses the necessary pathways and electron flow systems to accomplish methanotrophy. However, a complete reversal of methanogenesis pathway is thermodynamically infeasible unless coupled with an electronaccepting pathway $[25,26]$.

M. acetivorans, a strictly anaerobic marine methanogen possessing one of the largest known archaeal genomes [27], has emerged as a model archaeon owing to the availability of genetic tools [28] and versatility in substrate utilization [29,30]. While the pathways describing the metabolism on native substrates have been extensively studied [31-34], relevant pathways and electron flows for methane oxidation by $M$. acetivorans remain largely uncharacterized. Two genome-scale metabolic (GSM) models, iVS941 [35] and iMB745 [36], for this organism have been proposed. Both models, however, are not up to date with the current literature on the stoichiometry of ion transport across the membrane and ATP synthesis [37-42]. Recent findings on the electron flow mechanisms of $M$. acetivorans cell extracts grown with methane (unpublished observations, Zhen Yan and James G. Ferry) motivates an update in the existing genomescale models to incorporate recent findings and to allow for the analysis of methane utilization in silico.

In this paper we make use of a revamped GSM for $M$. acetivorans to postulate pathways for reversing methanogenesis while maintaining overall thermodynamic feasibility. We first generated an up-to-date GSM model for $M$. acetivorans by combining information from two earlier models (i.e., iVS941 and iMB745) along with the most recent data from literature and databases. $M$. acetivorans has transcriptome and proteome profiles that differ depending on growth substrate [31,34]. We augmented the updated gene-protein-reaction (GPR) associations with regulatory (i.e., $-\mathrm{R}$ ) switches to incorporate proteomics data to the updated metabolic reconstruction by switching on/off reactions for different substrates. Using the model as a starting point a thermodynamically feasible pathway is proposed for the co-utilization of methane and bicarbonate in the presence of $\mathrm{Fe}^{3+}, \mathrm{NO}_{3}{ }^{-}, \mathrm{SO}_{4}{ }^{2-}$, and $\mathrm{MnO}_{2}$ as external electron acceptors. Overall $\Delta \mathrm{G} \leq 0$ is imposed as a constraint to ensure thermodynamic feasibility of methanogenesis reversal in the presence of an external electron acceptor. The interplay between externally supplied electron acceptors and various byproducts is analyzed. The feasibility of methanotrophy by resting cells is assessed when all carbons coming from methane and bicarbonate are converted into acetate, formate, $\mathrm{CO}_{2}$, and methyl sulfide, the known byproducts of $M$. acetivorans' metabolism $[30,43]$ some of which were also observed recently by Wood et al. [44] as end products of methanotrophy by the archaeon.

\section{Results and discussion}

Updated genome-scale metabolic model reconstruction of $M$. acetivorans, iMAC868

iMAC868 contains 868 genes, 845 reactions, and 718 metabolites (Additional file 1) and provides better agreement with the observed growth yields on methanol and acetate compared to earlier reconstructions (see Table 1). Improved prediction is due to the correction of charge and mass imbalances of the reactions inherited from the previous metabolic models, incorporation of accurate ion exchange stoichiometries for membrane-bound reactions, and optimization of $\mathrm{Na}^{+} / \mathrm{H}^{+}$ratio for sodium/ proton antiporter (Mrp) and ATP synthase. Among the charge re-balanced reactions, those involving cofactor $\mathrm{F}_{420}$ in the methylotrophic pathway and ATP synthase also required proton rebalancing to accurately account for proton exchange across the cell membrane. The number of $\mathrm{Na}^{+}$pumped out by ferredoxin-dependent methanophenazine reductase (Rnf) was updated from three $\mathrm{Na}^{+}$in iMB745 [36] to four $\mathrm{Na}^{+}$per methanophenazine reduced in accordance with experimental findings [38]. In addition to this, the ATP synthase reaction was modified to co-utilize $\mathrm{Na}^{+}$and $\mathrm{H}^{+}$gradients [37]. Using the procedure described in Methods section, the optimal $\mathrm{Na}^{+} / \mathrm{H}^{+}$ratio recapitulating the growth yields on native substrates was estimated to be 2:1 for Mrp and 3:1 and 1:2 for ATP synthase, respectively. The two identified solutions for ATP synthase are rendered equivalent

Table 1 Growth yield predictions of iMAC868 model of $M$. acetivorans compared with predictions of previous models iVS941 [35] and iMB745 [36]

\begin{tabular}{lllll}
\hline Substrate & $\begin{array}{l}\text { Observed } \\
\text { growth yield }\end{array}$ & \multicolumn{3}{l}{ Predicted growth yield } \\
\cline { 3 - 5 } & & $\begin{array}{l}\text { iVS941 } \\
{[35]}\end{array}$ & $\begin{array}{l}\text { iMB745 } \\
{[36]}\end{array}$ & iMAC868 [this study] $^{\text {iMn }}$ \\
\hline Methanol & $5.2[69]$ & 9.5 & 4.0 & 5.26 \\
Acetate & $2.4[29]$ & 4.0 & 3.0 & 2.6 \\
\hline
\end{tabular}

Yield units are gram dry cell weight per mol of substrate 
by the reversible $2: 1$ antiport of $\mathrm{Na}^{+} / \mathrm{H}^{+}$across the cell membrane by Mrp, which makes one intracellular $\mathrm{H}^{+}$ equivalent to two extracellular $\mathrm{Na}^{+}$. We also added an $\mathrm{F}_{420}$-dependent NADP reductase to the iMAC868 model (personal communications with James G. Ferry), which functions as a source of NADPH for cell biosynthesis.

Upon correcting 64 GPRs based on updated gene annotations (Additional file 2) and implementing proteomicsdependent growth condition-specific R-GPR switches, iMAC868 correctly predicts gene knockout outcomes for 27 out of 28 mutants of $M$. acetivorans (see Table 2; Additional file 1 ). The only false prediction by the iMAC 868 model is missing the in vivo essentiality of the mutant lacking methanol-specific methyltransferases $(\triangle m t a A 1$ $\triangle m t a C B 1 \triangle m t a C B 2 \triangle m t a C B 3)$ growing with acetate due to the unknown role of the enzymes in acetate-grown cells [45]. The model correctly captures the essentiality of $m c h$ [46] by identifying the role of the methylotrophic pathway as a source of reduced $\mathrm{F}_{420}$ for NADPH production in acetate-grown cells thereby rendering $m c h$ (methenyl- $\mathrm{H}_{4} \mathrm{SPT}$ cyclohydrolase) essential. Comparing with the iVS941 model, the iMAC868 model correctly predicts the essentiality of $r n f, m t r$, and the membranebound $h d r$ due to the updated GPRs and ion transport stoichiometries included in this model.

\section{Model customization to capture methanotrophy by $M$. acetivorans}

In order to allow for methanotrophy, the iMAC868 model was customized to enable three new processes:
(1) reversal of methyl-coenzyme $M$ reductase (Mcr) reaction, (2) inclusion of a cytosolic methyltransferase $(\mathrm{CmtA})$, and (3) inclusion of a mechanism enabling electron bifurcation and its subsequent discharge to an external electron acceptor. The methyl-coenzyme $\mathrm{M}$ reductase of an anaerobic methanotroph (ANME-MCR), capable of oxidizing methane [47], was appended to the iMAC868 model upon deactivating the native Mcr to prevent methanogenesis based on evidence regarding the reversal of methanogenesis in $M$. acetivorans [23, 24, 48], reversibility of native Mcr [49], and the confirmed heterologous expression of ANME-MCR in M. acetivorans demonstrating ferric-dependent methanotrophy [44]. CmtA [50] serves as a soluble alternative to membranebound Mtr, allowing the conversion of methyl-coenzyme $\mathrm{M}$ to methyl-tetrahydrosarcinapterin without drawing on sodium ion gradients across the membrane. Cdh, a key enzyme in the modeled pathway, is dependent on ferredoxin to reduce $\mathrm{CO}_{2}$ that generates the carbonyl group in acetyl-CoA [51]. Two flavin-based mechanism are postulated in which an electron pair derived from oxidation of coenzyme B and coenzyme $\mathrm{M}\left(E_{\mathrm{m}}=-143 \mathrm{mV}\right)$ bifurcates yielding a high-potential electron reducing $\mathrm{Fe}^{3+}$ to $\mathrm{Fe}^{2+}\left(E_{\mathrm{m}}=+770 \mathrm{mV}\right)$ and a low-potential electron reducing ferredoxin $\left(E_{\mathrm{m}}=-420 \mathrm{mV}\right)$. Flavin-based electron bifurcation is common among anaerobic microbes including methanogens [52, 53]. Although, both postulated mechanisms depend on delivering electrons to $\mathrm{Fe}^{3+}$ on the outer aspect of the cytoplasmic membrane, the bifurcation event occurs either at the cytoplasm or the

Table 2 Gene deletion lethality predictions by iMAC868 model of M. acetivorans compared with predictions of previous models

\begin{tabular}{|c|c|c|c|c|c|c|c|}
\hline \multirow[t]{2}{*}{ Gene deletion } & \multicolumn{3}{|l|}{ Acetate } & \multicolumn{3}{|c|}{ Methanol } & \multirow[t]{2}{*}{ References } \\
\hline & iVS941 & iMB745 & iMAC868 & iVS941 & iMB745 & iMAC868 & \\
\hline$\Delta a c k \Delta p t a$ & NGNG & NGNG & NGNG & $\mathrm{GG}$ & GG & GG & {$[30]$} \\
\hline$\triangle h d r A B C$ & GG & GG & GG & GG & GG & GG & {$[70]$} \\
\hline$\triangle h d r E D$ & GNG & NGNG & NGNG & GNG & NGNG & NGNG & {$[70]$} \\
\hline$\Delta m c h$ & GNG & GNG & NGNG & NGNG & NGNG & NGNG & {$[46]$} \\
\hline$\triangle m t a A 1$ & GG & GG & GG & NGNG & NGNG & NGNG & {$[45]$} \\
\hline$\triangle m t a B 1 C 1 \triangle m t a B 2 C 2 \Delta m t a B 3 C 3$ & GG & GG & GG & NGNG & NGNG & NGNG & {$[45]$} \\
\hline$\triangle m t a A 1 \triangle m t a B 1 C 1 \Delta m t a B 2 C 2 \Delta m t a B 3 C 3$ & GNG & GNG & GNG & NGNG & NGNG & NGNG & {$[45]$} \\
\hline$\triangle m t b A$ & GG & GG & GG & GG & GG & GG & {$[45]$} \\
\hline$\Delta m t s D \Delta m t s F \Delta m t s H$ & $\mathrm{GG}$ & GG & $\mathrm{GG}$ & GG & $\mathrm{GG}$ & GG & {$[71]$} \\
\hline$\Delta m t s X \Delta m t s Y, X$ and $Y$ any two $m$ ts genes & GG & GG & GG & GG & $\mathrm{GG}$ & GG & {$[71]$} \\
\hline$\triangle r n f H C D G E A B F$ & GNG & NGNG & NGNG & GG & $\mathrm{GG}$ & $\mathrm{GG}$ & {$[70]$} \\
\hline$\Delta l y s K$ & GG & GG & GG & GG & GG & GG & {$[72]$} \\
\hline$\Delta$ lys & GG & GG & GG & GG & GG & GG & {$[72]$} \\
\hline$\Delta m t r$ & GNG & NGNG & NGNG & NGNG & NGNG & NGNG & [73] \\
\hline Total correct & $9 / 14$ & $12 / 14$ & $13 / 14$ & $13 / 14$ & $14 / 14$ & $14 / 14$ & \\
\hline
\end{tabular}

GG growth in silico/growth in vivo, GNG growth in silico/no growth in vivo, NGNG no growth in silico/no growth in vivo 
membrane. Bifurcation in the membrane depends on the Rnf complex, abundant in acetate-grown M. acetivorans, which interacts with ferredoxin and contains two FMNbound subunits that are possible sites for electron bifurcation [54]. Oxidation of coenzyme B and coenzyme M is catalyzed by the membrane-bound CoMS-SCoB heterodisulfide reductase (HdrDE) [54]. Methanophenazine (MP) is a quinone-like electron carrier that shuttles electrons between HdrDE and the Rnf complex. Importantly, the reduction of ferredoxin is not dependent on a sodium gradient. Bifurcation in the cytoplasm is postulated to be dependent on the fused HdrA2:MvhD protein shown previously to be present in acetate-grown $M$. acetivorans [34]. Oxidation of HS-CoB and HS-CoM is catalyzed by the soluble heterodisulfide reductase ( $\mathrm{HdrB} 2)$ that donates electrons to the flavin-containing $\mathrm{HdrA} 2$ component where bifurcation takes place reducing ferredoxin and transferring an electron to the membrane where reduction of $\mathrm{Fe}^{3+}$ takes place. Finally, an electron transfer reaction is included in the model to transfer the electrons from reduced methanophenazine to an externally supplied electron acceptor based on its reported in vivo essentiality $[19,20,55]$. The essentiality of this reaction was confirmed by the absence of any in silico external electron acceptor-independent thermodynamically feasible metabolic state despite allowing the production of all reported reduced products such as hydrogen gas [56] and organic acids such as acetate and formate [30]. These additions complete the pathways for the oxidation of methane to various end products such as acetate, formate and $\mathrm{CO}_{2}$. The addition of prospective biofuel molecule production pathways for ethanol [57], butanol [58], and isobutanol [59] to the model allows the exploration of their thermodynamically feasible maximum theoretical yields for different electron acceptors.

\section{Products of electron-acceptor-dependent AOM}

The model supports acetate, $\mathrm{CO}_{2}$ and biomass as the main products of methanotrophy using all tested electron acceptors. Methane is oxidized to methyl- $\mathrm{H}_{4} \mathrm{SPT}$ by ANME-MCR and Mtr (or CmtA), a part of which is oxidized via the methylotrophic pathway to produce intracellular $\mathrm{CO}_{2}$. The remaining methyl- $\mathrm{H}_{4} \mathrm{SPT}$ is used to produce acetyl-CoA, the primary building block for all biomass precursors. Additional carbon fixation occurs via reductive carboxylation by $\mathrm{Cdh}$ and Por. AcetylCoA is also converted to acetate, generating ATP via substrate-level phosphorylation (Fig. 1). The electrons released upon activation of methane by ANME-MCR are transferred to ferredoxin via soluble and membranebound electron transport chains involving flavin-based electron bifurcation mechanisms. In addition, further oxidation of methyl- $\mathrm{H}_{4} \mathrm{SPT}$ through methylotrophic pathway generates reducing equivalents in the form of ferredoxin and $F_{420}$. Fpo and Rnf complexes facilitate the transfer of electrons from reduced $F_{420}$ and ferredoxin, respectively, to the external electron acceptor via methanophenazine, thereby generating $\mathrm{H}^{+}$and $\mathrm{Na}^{+}$gradients across the membrane for chemiosmotic ATP synthesis (see Fig. 1). The primary carbon fixation mechanism via reductive carboxylation prompted a quantitative analysis of the impact of utilizing $\mathrm{CO}_{2}$ as a co-substrate in the form of bicarbonate on acetate and biomass yields.

Thermodynamic feasibility of methanotrophy is ensured only when the free energy of reduction $\left(\Delta \mathrm{G}_{\text {red }}\right)$ of the supplied electron acceptor is less than $50.5 \mathrm{~kJ} / \mathrm{elec}-$ tron-pair (Fig. 2), corresponding to the maximum free energy equivalents generated by $\mathrm{CO}_{2}$ production (see Table 3). Using methane as the sole carbon source, maximum biomass yield is constrained by thermodynamic feasibility when $\Delta \mathrm{G}_{\text {red }}$ of the electron acceptor is greater than $-20 \mathrm{~kJ} /$ electron-pair. Sulfate-dependent methanotrophy falls within this regime, in which thermodynamic coupling with an exergonic pathway such as acetate or $\mathrm{CO}_{2}$ production (Table 3 ) drives only partial conversion of methane to biomass. In contrast, biomass production is limited only by stoichiometry during ferric-dependent methanotrophy due to the far greater free energy equivalents produced by the reduction of $\mathrm{Fe}^{3+}$ to $\mathrm{Fe}^{2+}$ ( $\Delta \mathrm{G}=-140.44 \mathrm{~kJ} /$ electron-pair) compared to $\mathrm{SO}_{4}{ }^{2-}$ reduction $(\Delta \mathrm{G}=44.53 \mathrm{~kJ} /$ electron-pair). This thermodynamic advantage for $\mathrm{Fe}^{3+}$ allows for the co-utilization of bicarbonate up to a maximum $\mathrm{HCO}_{3}{ }^{-} / \mathrm{CH}_{4}$ ratio of 0.44 with complete incorporation of all substrate carbons into biomass. However, the endergonic nature of bicarbonate uptake disallows $\mathrm{HCO}_{3}{ }^{-} / \mathrm{CH}_{4}$ co-utilization for increasing biomass yield under sulfate-dependent methanotrophy. Methanotrophy using $\mathrm{NO}_{3}{ }^{-}$and $\mathrm{MnO}_{2}$ also allows for co-utilization of bicarbonate as both electron acceptors have $\Delta G_{\text {red }}$ greater than $-20 \mathrm{~kJ} /$ electron-pair (see Table 3).

The model predicts a maximum acetate production (0.5 $\mathrm{mol} / \mathrm{mol}$-methane), constrained only by stoichiometry for both $\mathrm{Fe}^{3+}$ and $\mathrm{SO}_{4}{ }^{2-}$ during growth on only methane. This yield is further increased to $0.94 \mathrm{~mol} /$ mol-methane at an optimal $\mathrm{HCO}_{3}{ }^{-} / \mathrm{CH}_{4}$ ratio of 0.88 for ferric-dependent methanotrophy, and $0.68 \mathrm{~mol} /$ mol-methane at an optimal $\mathrm{HCO}_{3}{ }^{-} / \mathrm{CH}_{4}$ ratio of 0.36 during sulfate-dependent methanotrophy (Fig. 3a). The improvement in acetate yield arises from the reduction in the fraction of methane oxidized via the methylotrophic pathway from 50 to $6 \%$ and $32 \%$ during ferricand sulfate-dependent methanotrophy, respectively. However, a complete reversal of the aceticlastic pathway with a co-utilization ratio of one could not be achieved using either electron acceptor due to thermodynamic 


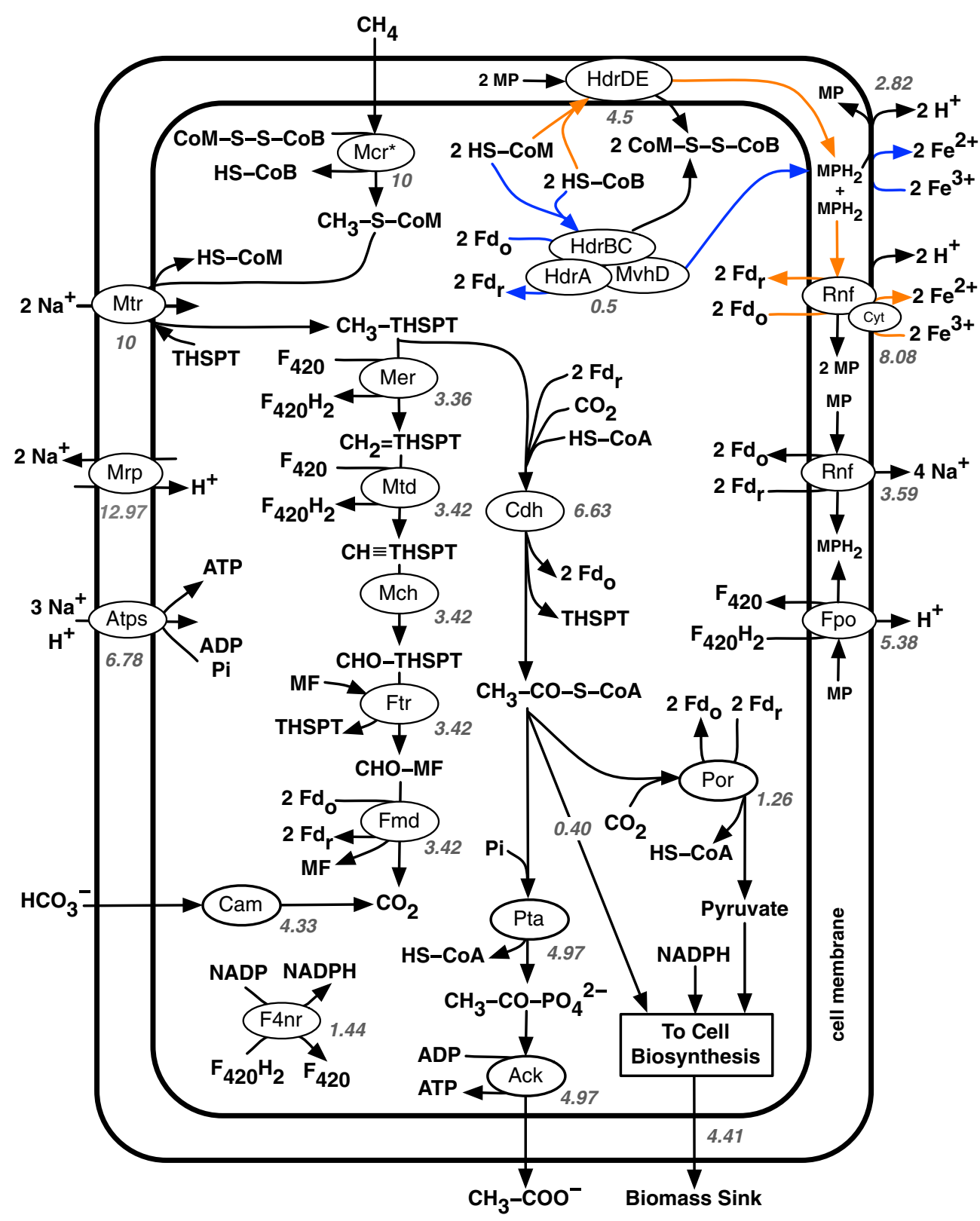

Fig. 1 Proposed methanogenesis reversal pathway supported by the iMAC868 model of M. acetivorans for co-metabolization of methane and bicarbonate in the presence of $\mathrm{Fe}^{3+}$ as external electron acceptor. Soluble and membrane-bound electron bifurcation routes are shown as blue and orange, respectively, and enzymes within ovals. In both routes, electrons originate from coenzyme B and coenzyme M. For enzymes with multiple subunits, only the subunits of soluble Hdr and Rnf involved in electron bifurcation are shown in detail. Numbers in italics next to enzyme ovals denote reaction fluxes (in mmol/gDCW-h) calculated under maximization of acetate production at bicarbonate to methane ratio of 0.44 . This ratio corresponds to the maximum thermodynamically feasible value ensuring biomass production at $30 \%$ of its theoretical maximum for $\mathrm{Fe}^{3+}$ as the electron acceptor. The flux towards growth was calculated by assuming that $1 \mathrm{~g}$ of biomass contains $36 \mathrm{mmol}$ of carbon. Intracellular proton and water stoichiometries are omitted for the sake of simplicity. Soluble methyltransferase $(\mathrm{CmtA})$ is not present in the network since the minimum possible flux through this reaction is zero. Mcr* putative ANME-like Mcr homolog to methyl-coenzyme M reductase, $H d r B C: H d r A: M v h D$ soluble ferredoxin-dependent heterodisulfide reductase, Mtr methyl-THSPT:coenzyme M methyltransferase, Mer methenyl-THSPT reductase, Mtd methenyl-THSPT dehydrogenase, Mch methenyl-THSPT cyclohydrolase, Ftr formylmethanofuran:THSPT formyltransferase, Fmd formylmethylfuran dehydrogenase, Cdh CO dehydrogenase, Pta phosphotransacetylase, Ack acetate kinase, Por pyruvate synthase, Atps ATP synthase, Mrp sodium/proton antiporter, Rnf methanophenazine reductase, Cyt cytochrome c subunit of Rnf complex, Fpo F ${ }_{420}$ dehydrogenase, Cam carbonic anhydrase, F4nr $\mathrm{F}_{420}$-dependent NADP reductase, THSPT tetrahydrosarcinapterin, MF methanofuran, MP methanophenazine, $\mathrm{MPH}_{2}$ reduced methanophenazine, $\mathrm{Fd}_{0}$ oxidized ferredoxin, $\mathrm{Fd}_{r}$ reduced ferredoxin, $\mathrm{F}_{420}$ coenzyme $\mathrm{F}_{420}, \mathrm{~F}_{420} \mathrm{H}_{2}$ reduced coenzyme $\mathrm{F}_{420}$ 


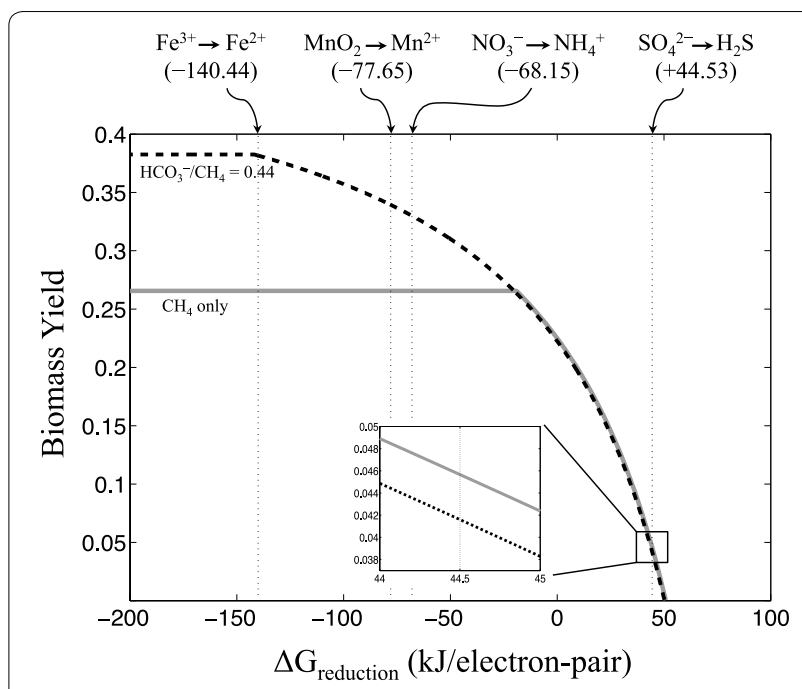

Fig. 2 Biomass yield (per $10 \mathrm{mmol}$ methane) as a function of the $\Delta \mathrm{G}$ of external electron acceptor reduction (kJ/electron-pair) predicted by the iMAC868 model of M. acetivorans. Solid line methane as the sole carbon source; dashed line bicarbonate and methane (at a ratio of $\mathrm{HCO}_{3}{ }^{-} / \mathrm{CH}_{4}=0.44$ ) as carbon sources. Vertical dotted lines show the $\Delta \mathrm{G}$ (kJ/electron-pair) of reduction for $\mathrm{Fe}^{3+}(-140.44), \mathrm{MnO}_{2}$ $(-77.65), \mathrm{NO}_{3}{ }^{-}(-68.15)$, and $\mathrm{SO}_{4}{ }^{2-}(+44.53)$. A magnified insert shows the maximum biomass yields for sulfate-dependent methanotrophy. All $\Delta \mathrm{G}$ values were evaluated at $\mathrm{pH}$ of $7,25^{\circ} \mathrm{C}$, and an ionic strength of $0.25 \mathrm{M}$ as described by Alberty [64]

restrictions during sulfate-dependent methanotrophy and reduced ferredoxin availability during ferricdependent methanotrophy. Under sulfate-dependent methanotrophy, the minimum essential flux through the methylotrophic pathway enables thermodynamic coupling with sulfate reduction for the generation of free energy equivalents. Mandatory channeling of electrons towards ferric ions by the electron bifurcation mechanism decreases available reduced ferredoxin for acetate synthesis during ferric-dependent methanotrophy. Despite the exergonic nature and the ATP generating capability of the acetate production pathway, it is never essential (minimum acetate production is always zero) at any $\mathrm{HCO}_{3}{ }^{-} / \mathrm{CH}_{4}$ ratio due to the fact that there exist other competing products and an electron acceptor-driven chemiosmotic ATP synthesis.

$\mathrm{CO}_{2}$ production remains non-essential during ferricdependent methanotrophy as revealed by the model (Fig. $3 \mathrm{~b}$ ) due to the fact that reductive carboxylation of acetyl-CoA allows the production of many different thermodynamically feasible products. In contrast, $\mathrm{CO}_{2}$ production for sulfate-dependent methanotrophy beyond a $\mathrm{HCO}_{3}{ }^{-} / \mathrm{CH}_{4}$ ratio of 0.36 becomes mandatory. Beyond this ratio, increased $\mathrm{CO}_{2}$ production via the methylotrophic pathway serves to offset the free energy increase associated with uptake of bicarbonate. Carbon channeling towards the methylotrophic pathway leads to increased $\mathrm{CO}_{2}$ production thus decreasing methane flow towards other major products, thereby adversely affecting acetate and biomass yields at $\mathrm{HCO}_{3}{ }^{-} / \mathrm{CH}_{4}$ ratios beyond 0.36 . The trade-off plot between the products of $\mathrm{AOM}$ and biomass did not reveal any thermodynamic restrictions in the solution space during ferric-dependent methanotrophy (Fig. 3c, d). However, the model predicts that acetate becomes thermodynamically constrained beyond a biomass yield of 0.018 for sulfate-dependent methanotrophy. Up to this yield value, the minimum required $\mathrm{CO}_{2}$ production remains zero due to the fact that either acetate or $\mathrm{CO}_{2}$ production pathways can generate the necessary free energy equivalents, ATP and reducing equivalents for biomass production. At biomass yields above $0.018, \mathrm{CO}_{2}$ production becomes mandatory.

Table 3 Oxidation half reactions of methane to various products and reduction half reactions of various electron acceptors

\begin{tabular}{lcc}
\hline Oxidation half reactions & $\boldsymbol{\Delta G}$ (kJ/mole product) & $\Delta \mathbf{G}(\mathbf{k J} / \mathbf{m o l e ~ m e t h a n e )}$ \\
\hline $\mathrm{CH}_{4}+2 \mathrm{H}_{2} \mathrm{O} \rightarrow \mathrm{CO}_{2}+8 \mathrm{H}^{+}+8 e^{-}$ & -202.79 & -202.79 \\
$2 \mathrm{CH}_{4}+2 \mathrm{H}_{2} \mathrm{O} \rightarrow \mathrm{CH}_{3} \mathrm{COOH}+8 \mathrm{H}^{+}+8 e^{-}$ & -193.44 & -96.72 \\
$4 \mathrm{CH}_{4}+\mathrm{H}_{2} \mathrm{O} \rightarrow \mathrm{CH}_{3} \mathrm{CH}_{2} \mathrm{CH}_{2} \mathrm{CH}_{2} \mathrm{OH}+8 \mathrm{H}^{+}+8 e^{-}$ & -113.48 & -28.37 \\
$4 \mathrm{CH}_{4}+\mathrm{H}_{2} \mathrm{O} \rightarrow \mathrm{CH}_{3} \mathrm{CH}\left(\mathrm{CH}_{3}\right) \mathrm{CH}_{2} \mathrm{OH}+8 \mathrm{H}^{+}+8 e^{-}$ & -104.87 & -26.22 \\
$2 \mathrm{CH}_{4}+\mathrm{H}_{2} \mathrm{O} \rightarrow \mathrm{CH}_{3} \mathrm{CH} \mathrm{H}_{2} \mathrm{OH}+4 \mathrm{H}^{+}+4 e^{-}$ & -31.06 & -15.53 \\
$\mathrm{CH}_{4}+\mathrm{H}_{2} \mathrm{O} \rightarrow \mathrm{CH}_{3} \mathrm{OH}+2 \mathrm{H}^{+}+2 e^{-}$ & +14.83 & +14.83 \\
\hline Reduction half reactions & $\mathbf{G}$ (kJ/mole oxidant) & $\Delta \mathbf{G}(\mathbf{k J} / \mathbf{e l e c t r o n - p a i r )}$ \\
\hline $\mathrm{Fe}^{3+}+e^{-} \rightarrow \mathrm{Fe}^{2+}$ & -70.22 & -140.44 \\
$\mathrm{MnO}_{2}+4 \mathrm{H}^{+}+2 e^{-} \rightarrow \mathrm{Mn}^{2+}+2 \mathrm{H}_{2} \mathrm{O}$ & -77.65 & -77.65 \\
$\mathrm{NO}_{3}^{-}+10 \mathrm{H}^{+}+8 e^{-} \rightarrow \mathrm{NH}_{4}^{+}+3 \mathrm{H}_{2} \mathrm{O}$ & -272.75 & -68.15 \\
$\mathrm{SO}_{4}^{2-}+10 \mathrm{H}^{+}+8 e^{-} \rightarrow \mathrm{H}_{2} \mathrm{~S}+4 \mathrm{H}_{2} \mathrm{O}$ & +178.14 & +44.53
\end{tabular}



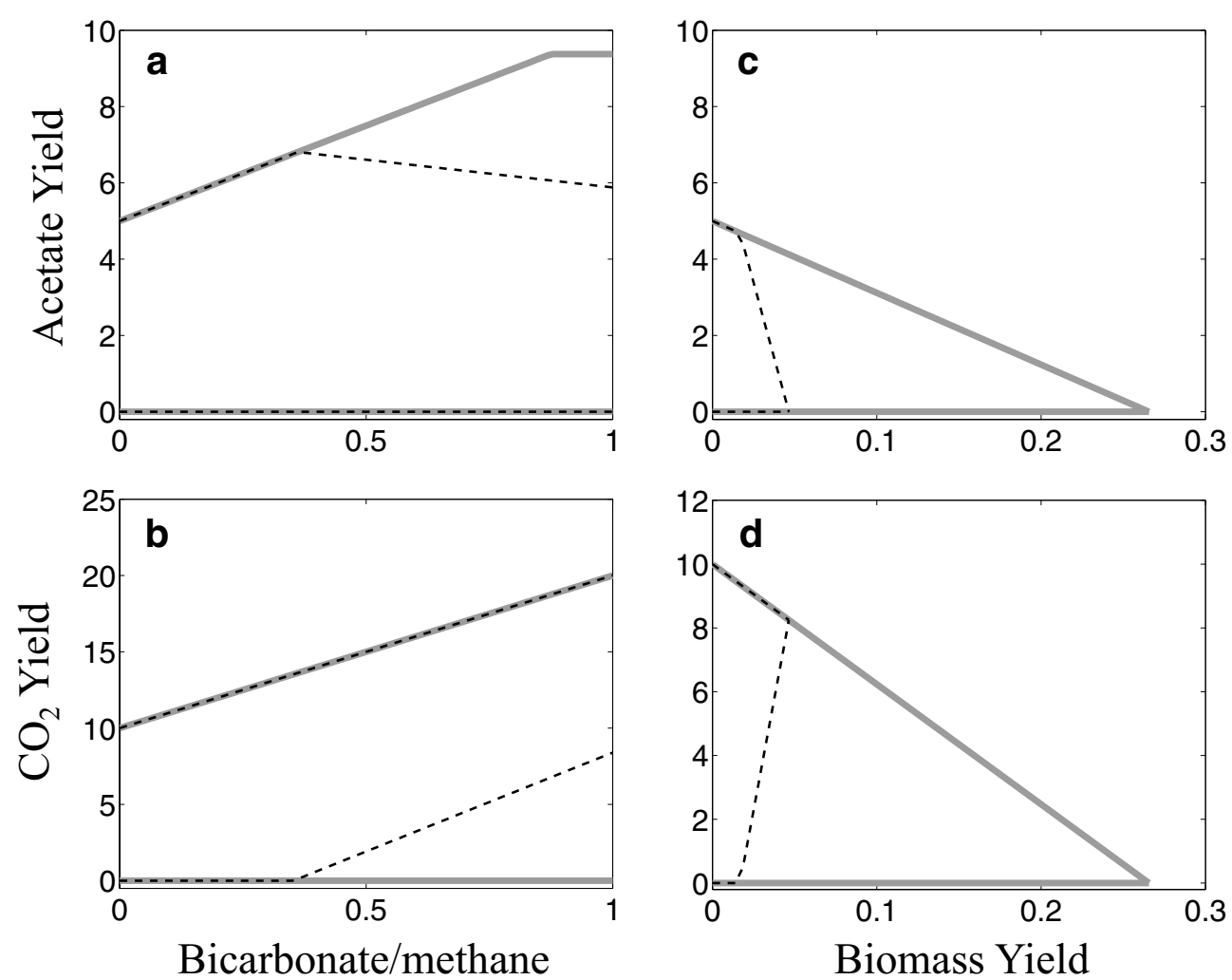

Fig. 3 Acetate and carbon dioxide production yields as a function of bicarbonate to methane ratio (a, b) and biomass yield (c, d) using Fe ${ }^{3+}$ (solid lines) or $\mathrm{SO}_{4}{ }^{2-}$ (dashed lines) as external electron acceptors. Methane was the sole carbon source for generating the plots shown in panels (c) and (d). All yields are per $10 \mathrm{mmol}$ of methane

The production of ethanol, butanol, isobutanol, and methanol is thermodynamically feasible through both ferric-dependent and sulfate-dependent methanotrophy (Fig. 4). However, complete carbon conversion of methane to candidate biofuel molecules is thermodynamically feasible only for ferric-dependent methanotrophy with methane as the sole carbon source (Fig. 4a) due to the favorable thermodynamics of coupling the biofuel production pathways by ferric reduction (see Table 3). Upon co-utilization of methane and bicarbonate, electron bifurcation limits the availability of reduced ferredoxin for fixing $\mathrm{CO}_{2}$ by $\mathrm{Cdh}$ to produce acetyl-CoA (biofuel precursor), thereby restricting maximum achievable biofuel yield (Fig. 4a). Moreover, biofuel production pathways require additional energy in the form of $\mathrm{NAD}(\mathrm{P}) \mathrm{H}$ necessitating elevated amounts of reduced $\mathrm{F}_{420}$ at increasing bicarbonate to methane ratios which is also controlled by electron bifurcation. Incorporation of bicarbonate into methanol occurred via the $\mathrm{CO}_{2}$ reduction pathway (reversal of the methylotrophic pathway) as opposed to $\mathrm{CO}_{2}$ reduction by acetyl-CoA synthesis, causing all electrons to be generated by the ANME-MCR. During sulfatedependent methanotrophy, none of the products could be produced with the complete carbon conversion efficiency due to the fact that coupling biofuel production with $\mathrm{SO}_{4}{ }^{2-}$ reduction remains thermodynamically infeasible (see Table 3) requiring the co-production of by-products such as acetate or $\mathrm{CO}_{2}$. As a consequence of this, co-utilization of bicarbonate and methane is not supported (see Fig. 4b). Although both oxidation of methane to methanol and reduction of sulfate to sulfide are thermodynamically infeasible, methanol can be still produced with $\mathrm{SO}_{4}{ }^{2-}$ due to coupling with the concomitant production of $\mathrm{CO}_{2}$. The lower bound for the production of all biofuel molecules is zero indicating that their production is not growth-coupled when methane is either the sole carbon source or coutilized with bicarbonate.

\section{Interplay between electron acceptors and by-products of AOM at no growth}

The interplay between the external electron acceptor choice and various products of AOM is pictorially illustrated (see Fig. 5) using feasible production envelopes for growth-arrested cells. We constrained the model for zero growth, ATP production for only maintenance requirements, and bicarbonate to methane ratio of 0.44 . Analysis 


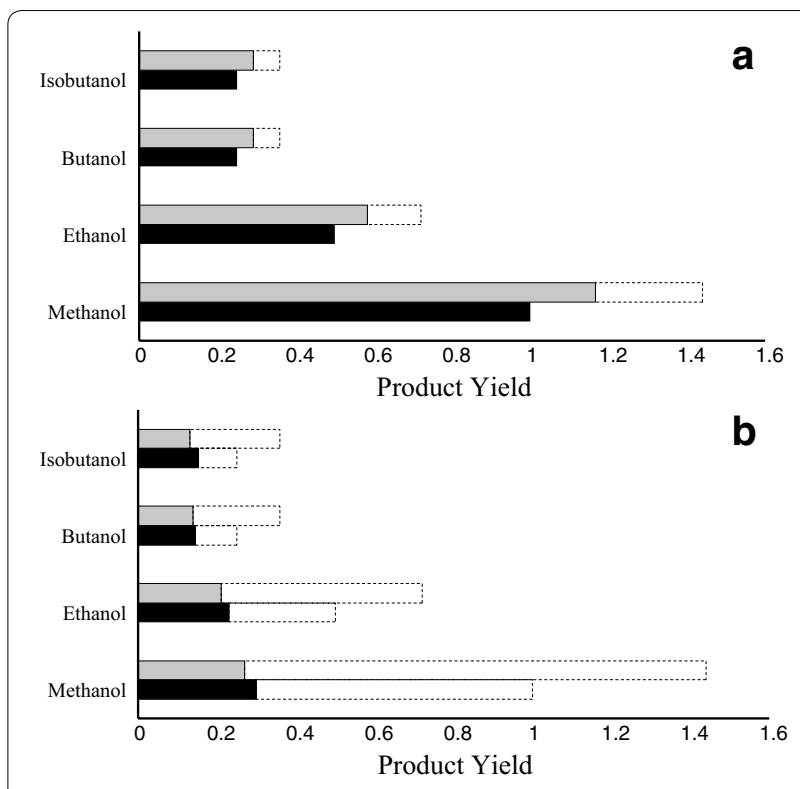

Fig. 4 Biofuel yields using methane (shaded in black) as the sole carbon source and $\mathrm{HCO}_{3}{ }^{-} / \mathrm{CH}_{4}$ (shaded in gray) with a ratio of 0.44 for ferric-dependent (a) and sulfate-dependent (b) methanotrophy. The dashed bars denote the excess carbons that could not be incorporated into the product due to thermodynamic restrictions. Ferricdependent methanotrophy predicted increased yields at higher $\mathrm{HCO}_{3}{ }^{-} / \mathrm{CH}_{4}$ ratios, but the carbon conversion was less than $100 \%$. Sulfate-dependent methanotrophy cannot achieve $100 \%$ carbon conversion at any $\mathrm{HCO}_{3}{ }^{-} / \mathrm{CH}_{4}$ ratio due to mandatory co-production of thermodynamically feasible by-products. Product yields are in mol per mol methane

of the product profiles predicted by the iMAC 868 model, based on the imposed constraints, identifies acetate as the main product of co-utilization of methane with bicarbonate along with the possible production of formate, $\mathrm{CO}_{2}$, and methyl sulfide (Fig. 5). A minimum $\mathrm{Fe}^{3+}$ uptake (i.e., $0.5 \mathrm{~mol} / \mathrm{mol}$-methane) is necessary to maintain thermodynamic feasibility of the observed solution spaces (Fig. 5a-d) at which methyl sulfide is found to be essential (Fig. 5a) due to the fact that it is the least oxidized by-product of methanotrophy by $M$. acetivorans. The maximum methyl sulfide yield at this $\mathrm{Fe}^{3+}$ uptake exceeds methane uptake indicating that bicarbonate is reduced via the methylotrophic pathway. The reversal of the methylotrophic pathway, however, is limited by the availability of reducing equivalents provided by Mcr, thereby resulting in an incomplete conversion of substrate carbons (methane and bicarbonate) to methyl sulfide. Increasing $\mathrm{Fe}^{3+}$ uptake allows more flux through the methylotrophic pathway, thereby generating additional intracellular $\mathrm{CO}_{2}$ for an increased acetate production of up to a maximum of $0.71 \mathrm{~mol} / \mathrm{mol}$-methane at an $\mathrm{Fe}^{3+}$ uptake of $2.2 \mathrm{~mol} / \mathrm{mol}$-methane (Fig. $5 \mathrm{~b}$ ). At this uptake rate, acetate can be produced as the sole product
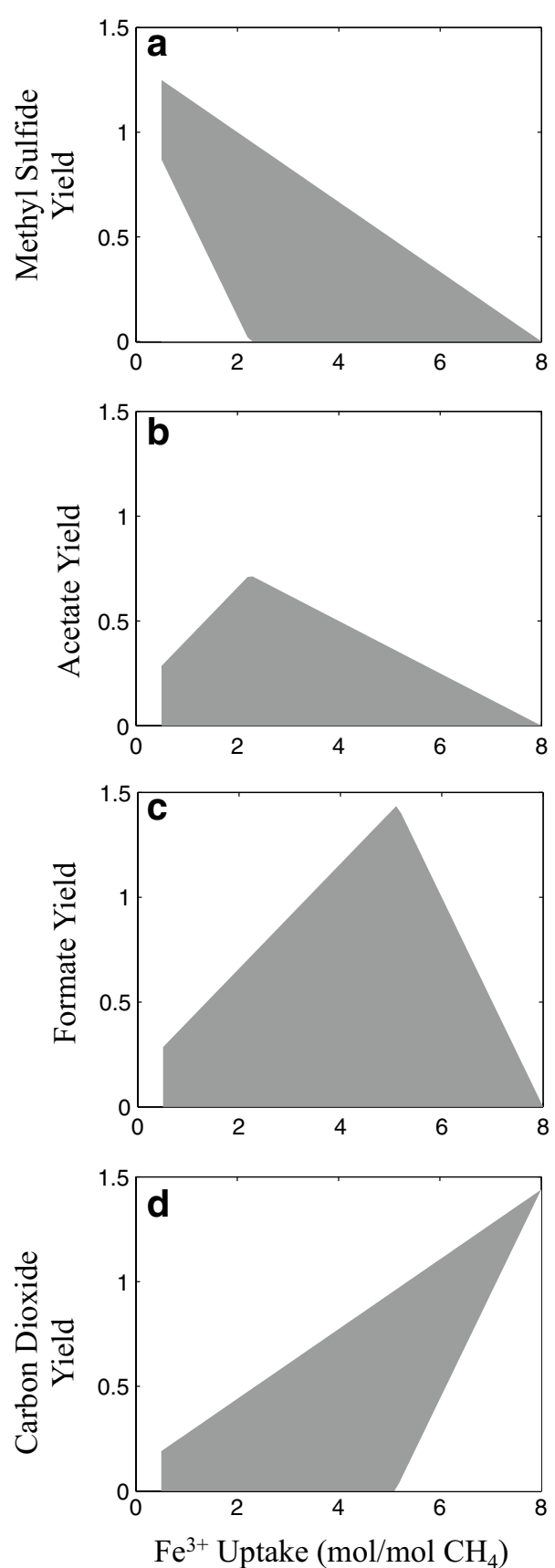

Fig. 5 Thermodynamically feasible production envelope (highlighted in grey) of methyl sulfide (a), acetate (b), formate (c), and carbon dioxide (d) as a function of $\mathrm{Fe}^{3+}$ uptake predicted by the iMAC 868 model under no growth. All product yields and $\mathrm{Fe}^{3+}$ uptake are defined as mol per mol methane

of methanotrophy resulting in non-essentiality of methyl sulfide production. Beyond this $\mathrm{Fe}^{3+}$ uptake rate, acetate production decreases due to the paucity of methyl-coenzyme $\mathrm{M}$ arising from increased flux through the methylotrophic pathway and channeling of electrons towards 
$\mathrm{Fe}^{3+}$ reduction via the membrane-bound electron transport chain. This increase in methylotrophic pathway flux also increases the yield of formate, an intermediate of this pathway. Maximum formate yield is found to be $1.44 \mathrm{~mol} / \mathrm{mol}$-methane at a Fe ${ }^{3+}$ uptake of $5.1 \mathrm{~mol} / \mathrm{mol}$ methane (Fig. 5c) where all taken up carbons are converted to formate. Beyond this $\mathrm{Fe}^{3+}$ uptake rate, $\mathrm{CO}_{2}$ production becomes essential so as to generate sufficient electrons for reduction of $\mathrm{Fe}^{3+}$ (Fig. 5d). A consequence of the essentiality of $\mathrm{CO}_{2}$ is the reduction of maximum formate yield. At a maximum $\mathrm{Fe}^{3+}$ uptake of $8 \mathrm{~mol} / \mathrm{mol}-$ methane, only $\mathrm{CO}_{2}$ is produced due to the fact that it is the most oxidized form of carbon that can be produced by $M$. acetivorans.

\section{Conclusions}

An updated genome-scale metabolic reconstruction (iMAC868) for the archaeon Methanosarcina acetivorans that integrates the latest literature findings and provides complete pathways and electron flow systems for reversing methanogenesis is introduced. Upon improving growth and gene-knockout outcome prediction for $M$. acetivorans grown on its native substrates, the model was used in a prospective mode for assessing thermodynamically feasible methanotrophic pathways leading to the production of biofuel candidate molecules such as methanol, ethanol, butanol, and isobutanol. We found that anaerobic methanotrophy favored the production of acetate and $\mathrm{CO}_{2}$ as they provide free energy equivalents to support growth. Co-utilization of $\mathrm{CO}_{2}$ (in the form of bicarbonate) and methane was feasible for certain ratios leading to improved carbon yields for acetate and biofuel molecules. Re-routing of a fraction of carbon towards $\mathrm{CO}_{2}$ was found to be a recurring mechanism for driving growth and production within thermodynamically constrained metabolic states. Finally, the availability in excess of inorganic electron acceptors resulted in a switch between substrate-level and chemiosmotic ATP synthesis. Thermodynamic constraints were often the limiting factor in product yields. Unsurprisingly, the inability to completely reverse the aceticlastic pathway in the absence of an external electron acceptor was confirmed.

The theoretical limits of external electron acceptor utilization possibilities to drive the reversal of methanogenesis were thoroughly explored. Key challenges that confound the fidelity of model predictions are still unknown sodium gradient requirements, substratedependent regulation and the detailed mechanism of electron transport from internal electron carriers to their external counterparts. Shedding light to these questions will require systematic experimental investigations to confirm or refute electron flow paths guided by the rapidly expanding modeling infrastructure.

\section{Methods \\ Model assembly and growth/product formation predictions}

The updated genome-scale metabolic model for $M$. acetivorans, iMAC868, was constructed by appending genes and reactions from iVS941 to iMB745. The stoichiometric coefficients of the ions associated with the membrane-bound electron transport chain were updated based on recent findings. This includes Rnf, ATP synthase and the $\mathrm{Na}^{+} / \mathrm{H}^{+}$ antiporter Mrp. All reactions in the model were checked for mass and charge balances and corrected if necessary. Five reactions from amino acid, two from tRNA, one from cofactor biosynthesis pathways, three from methanogenesis, and three metabolite transport reactions required elemental and charge rebalancing. The biomass equation formulation of iMB745 model was adopted in the new iMAC868 model as reported previously [36]. It was ensured that all biomass precursors could be independently produced in the model to avoid feasibiltiy tolerance related errors [60]. The iMAC868 model is available in Excel format in Additional file 1. All reaction fluxes are in $\mathrm{mmol} / \mathrm{gDCW}$-h except for the reaction representing cell biomass formation that is expressed in $\mathrm{h}^{-1}$. The medium composition was assumed to be a defined high-salt medium [29]. The model was assembled in a format compatible for flux balance analysis [61]. FBA optimization problems were solved by GNU Linear Programming Kit (GLPK) (http://www.gnu.org/software/glpk/) and Gurobi (http://www.gurobi.com) solvers in Matlab using COBRA toolbox [62]. Flux variability analysis (FVA) was performed to obtain range of fluxes under optimal growth conditions as described previously [63]. Both FBA and FVA problems incorporated overall thermodynamic feasibility constraints (overall $\Delta \mathrm{G} \leq 0$ ). FBA was performed by solving the following Linear Programming (LP) problem:

$$
\begin{aligned}
& \text { Maximize } v_{\text {biomass }} \\
& \text { Subject to } \sum S_{i j} v_{j}=0, \quad \forall i \in I, j \in J \\
& \sum_{j}^{j} \Delta G_{j} v_{j} \leq 0, \quad \forall j \in J^{e x} \cup\{\text { biomass }\} \\
& L B_{j} \leq v_{j} \leq U B_{j}, \quad \forall j \in J \backslash\{E x-\text { methane, ATPM }\} \\
& v_{\text {Ex-methane }}=-10 \\
& v_{A T P M} \geq 2.5 \\
& \Delta G_{j}=\Delta G_{j}^{m e t}, \quad \forall j \in J^{e x} \cup\{\text { biomass }\} \\
& v_{j} \in \mathbb{R} \quad \forall j \in J
\end{aligned}
$$

where sets, variables, and parameters are defined as follows: Sets:

$I=\{i \mid i=1,2, \ldots, M\}=$ Set of metabolites in the stoichiometric model

$J=\{j \mid j=1,2, \ldots, N\}=$ Set of reactions in the stoichiometric model 
$J^{e x}=\left\{j \mid j=1,2, \ldots, N^{e x}\right\}=$ Set of exchange reactions in the stoichiometric model

Variables:

$v_{j}=$ Flux of reaction $j \in J$

$v_{\text {biomass }}=$ Flux of the biomass formation reaction

Parameters:

$S_{i j}=$ Stoichiometric coefficient of metabolite $i \in I$ in reaction $j \in J$

$U B_{j}=$ Upper bound for the flux of reaction $j \in J$

$L B_{j}=$ Lower bound for the flux of reaction $j \in J$

$v_{E x-\text { methane }}=$ Flux of the methane exchange reaction

$v_{A T P M}=$ Flux of the non-growth associated maintenance ATP reaction

$\Delta G_{j}^{m e t}=$ The $\Delta G$ of formation of the metabolite associated with exchange reaction $j \in J^{e x} \cup\{$ biomass $\}$

All standard transformed $\Delta G$ values were calculated at $\mathrm{pH}$ of 7 , temperature of $25^{\circ} \mathrm{C}$ and ionic concentration of $0.25 \mathrm{M}$ [64] listed in Additional file 1. The upper bound of the free energy of biomass formation $\left(\Delta G_{\text {biomass }}\right)$ is estimated to be $3750 \mathrm{~J} / \mathrm{gDCW}$. This value is identified so as the overall stoichiometries for growth on acetate and methanol (see below) remain thermodynamically feasible:

$$
\begin{aligned}
& 10 \mathrm{CH}_{3} \mathrm{COOH} \rightarrow 9.3 \mathrm{CH}_{4}+9.3 \mathrm{CO}_{2}+0.026 \text { biomass } \\
& 10 \mathrm{CH}_{3} \mathrm{OH} \rightarrow 6.4 \mathrm{CH}_{4}+1.5 \mathrm{CO}_{2}+6 \mathrm{H}_{2} \mathrm{O}+0.052 \text { biomass }
\end{aligned}
$$

The iMAC868 model arrived at these overall conversion stoichiometries by solving the FBA problem subject to constraints (1), (3), and (5) only.

In the above LP problem, the flux of the biomass is maximized subject to the constraints of stoichiometry (1), thermodynamics (2), metabolic network fluxes (3), fixed uptake of methane (4), minimum requirements of maintenance ATP of $2.5 \mathrm{mmol} / \mathrm{gDCW}$-h (5), and fixed $\Delta G$ values of input/output metabolites to/from the system (6). Flux ranges for target products were obtained by iteratively solving the above LP problem to minimize and maximize all $v_{j}$ separately subject to stoichiometric and thermodynamic constraints.

\section{Formulation of R-GPR to integrate '-omics' data into the metabolic model}

Gene-protein-reactions (GPRs) associations in the iMAC868 model were thoroughly assessed and 64 GPRs were corrected using a list of 781 newly revised gene annotations (Additional file 2) along with database entries from KEGG [65], MetaCyc [66], BRENDA [67], and TransportDB [68]. Following this, R-GPR switches were implemented using a dataset of quantitative protein levels for over 250 genes of $M$. acetivorans grown with acetate and methanol [34]. This dataset is given in Additional file 1. The R-GPR approach allows for the incorporation of 'omics' data for conditional switching on/off of reactions allowing improved gene-knockout predictions by providing an insight into the likelihood of a reaction to be active or inactive under specific growth conditions. The following systematic procedure elaborates this conditional activation/inactivation of reactions by the R-GPR switches:

Step 1 Calculate the ratio of protein abundance under different growth substrates. For each gene $k$ in the total gene set $K$, the value $c_{k}$ was calculated as the ratio of protein abundance for cells grown on substrate 1 to cells grown on substrate 2 where substrate 1 and 2 can be any of acetate or methanol.

Step 2 Compare the ratio $c_{k}$ with a pre-defined cutoff value (i.e., equal to $25 \%$ ). If the ratio $c_{k}$ is below or equal to the cutoff value then gene $k$ is added to a candidate list $G$ for which the feasibility of removing the corresponding reactions is evaluated.

Step 3 Re-evaluate GPRs within list G. The GPR for each reaction is re-evaluated assuming that all genes in list $G$ are eliminated. If re-evaluation of the GPR reveals no associated gene then the reaction is added to the set $J^{\text {exp }}$ that contains the candidate reactions for removal.

Step 4 The following mathematical formulation is used to identify the maximum number of reactions in the set $J^{\text {exp }}$ that can be removed from the model without dropping the biomass yield below the experimental value:

$$
\begin{array}{lll}
\text { Minimize } & \sum_{j \in J_{\text {exp }} y_{j}} & \\
\text { Subject to } & \sum_{j} S_{i j} v_{j}=0, & \forall i \in I, j \in J \\
& y_{j} L B_{j} \leq v_{j} \leq y_{j} U B_{j}, & \forall j \in J^{\text {exp }} \backslash\left(J^{\text {on }} \cup J^{\text {off }}\right) \\
& L B_{j} \leq v_{j} \leq U B_{j}, & \forall j \in\left(J J^{\text {exp }}\right) \cup J^{\text {on }} \\
& v_{j}=0 & \forall j \in J^{\text {off }} \\
& v_{\text {biomass }} \geq v_{\text {biomass,exp }} & \\
& v_{j} \in \mathbb{R}, y_{j} \in\{0,1\} & \forall j \in J
\end{array}
$$

where sets, variables, and parameters in this MILP problem have the same definition as those defined earlier for the LP problem except for the followings: 
Table 4 SSE between predicted (by iMAC868) and observed growth yields for acetate- and methanol-grown cells at different ratios of $\mathrm{Na}^{+}$and $\mathrm{H}^{+}$exchange by Mrp antiporter and varying ratios of $\mathrm{Na}^{+}$and $\mathrm{H}^{+}$uptake by ATP synthase

\begin{tabular}{|c|c|c|c|c|c|c|}
\hline \multirow[t]{2}{*}{ Substrate } & \multirow{2}{*}{$\begin{array}{l}\text { Ratio of } \mathrm{Na}^{+} \text {to } \mathrm{H}^{+} \\
\text {exchange by } \\
\text { Mrp antiporter }\end{array}$} & \multicolumn{5}{|c|}{ Ratio of $\mathrm{Na}^{+}$to $\mathrm{H}^{+}$uptake by ATP synthase } \\
\hline & & $3: 1$ & $1: 1$ & $1: 3$ & $2: 1$ & $1: 2$ \\
\hline \multirow[t]{5}{*}{ Methanol } & $3: 1$ & $2.11 \mathrm{E}-04$ & $7.75 \mathrm{E}-06$ & $2.21 \mathrm{E}-04$ & $1.75 \mathrm{E}-02$ & $2.53 \mathrm{E}-05$ \\
\hline & $2: 1$ & $1.40 E-07$ & $8.58 \mathrm{E}-05$ & $2.86 \mathrm{E}-04$ & 1.67E-04 & $1.40 E-07$ \\
\hline & $1: 1$ & 4.57E-04 & 4.57E-04 & 4.57E-04 & $8.33 \mathrm{E}-05$ & $8.33 \mathrm{E}-05$ \\
\hline & $1: 2$ & $1.39 E-03$ & $6.73 E-04$ & $1.43 E-04$ & $1.43 E-04$ & $3.32 \mathrm{E}-05$ \\
\hline & $1: 3$ & $1.57 \mathrm{E}-03$ & $5.44 \mathrm{E}-04$ & $1.26 \mathrm{E}-06$ & $1.73 \mathrm{E}-04$ & $1.78 \mathrm{E}-04$ \\
\hline \multirow[t]{5}{*}{ Acetate } & $3: 1$ & 7.97E-06 & $2.13 \mathrm{E}-04$ & Infeasible & $3.93 \mathrm{E}-02$ & $4.76 \mathrm{E}-05$ \\
\hline & $2: 1$ & $8.00 E-06$ & $7.34 \mathrm{E}-05$ & $2.96 \mathrm{E}-04$ & $3.44 \mathrm{E}-04$ & $8.00 E-06$ \\
\hline & $1: 1$ & $8.05 E-06$ & $8.05 E-06$ & $8.05 E-06$ & $5.51 \mathrm{E}-04$ & $5.51 \mathrm{E}-04$ \\
\hline & $1: 2$ & $8.09 \mathrm{E}-06$ & $1.82 \mathrm{E}-04$ & $7.45 E-04$ & $7.45 \mathrm{E}-04$ & 2.10E-03 \\
\hline & $1: 3$ & $8.10 E-06$ & $3.45 \mathrm{E}-04$ & $1.74 \mathrm{E}-03$ & $8.36 \mathrm{E}-04$ & $3.34 \mathrm{E}-03$ \\
\hline
\end{tabular}

Only the 2:1 ratio of $\mathrm{Na}^{+}$and $\mathrm{H}^{+}$for Mrp satisfies the closest match between predicted and observed growth yields for both substrates. ATP synthase can uptake either $3 \mathrm{Na}^{+}$and $1 \mathrm{H}^{+}$(bold italics) or $1 \mathrm{Na}^{+}$and $2 \mathrm{H}^{+}$(italics), which are rendered equivalent by Mrp. Infeasibility arises from the inability to meet minimum ATP requirements

Sets:

$J^{\exp }=\left\{j \mid j=1,2, \ldots, N^{\exp }\right\}=$ Set of reactions whose GPRs are evaluated due to availability of experimental data (i.e., proteomic data)

$J^{o n}=\left\{j \mid j=1,2, \ldots, N^{o n}\right\}=$ Set of reactions for which the evaluation of their GPR indicates active reactions $J^{o f f}=\left\{j \mid j=1,2, \ldots, N^{o f f}\right\}=$ Set of reactions for which the evaluation of their GPR indicates inactive reactions

Variables:

$v_{\text {biomass }}=$ Flux of the reaction producing biomass

$y_{j}=$ Binary variable associated with flux of $v_{j}$

Parameters:

$v_{\text {biomass,exp }}=$ The experimentally measured biomass yield for the given substrate

Here, the sum of binary variables $y_{j}$ is minimized subject to the limitations on stoichiometry (7), the flux of the reactions for which proteomic data is available but their GPRs are not evaluated because $c_{k}$ is greater than the cutoff value (8), the flux of all other metabolic network reactions which do not belong to set $J^{\exp }$ along with those belong to set $J^{o n}(9)$, and the flux reactions which belong to set $J^{\text {off }}(10)$, and the flux of the reaction producing biomass being equal or greater than the experimentally measured biomass yield for the given substrate (11).

\section{Representation of external electron acceptor in the metabolic network of iMAC868}

Electron acceptor reactions are modeled using "electron acceptor equivalents (EAE)", which serves to drain electron pairs from the model. Each electron pair is drained from reduced methanophenazine. The general form of the electron acceptor reaction used in this model is:

$$
\begin{aligned}
& \text { Reduced methanophenazine }+a H^{+}[c] \\
& \quad \rightarrow \text { Oxidized methanophenazine }+E A E+b H^{+}[e]
\end{aligned}
$$

here, $\mathrm{a}$ and $\mathrm{b}$ correspond to the excess protons drained from the cytosol and secreted into the extracellular medium, respectively. These values are electron acceptor specific and can be obtained from the corresponding electron acceptor reduction reactions described in Table 3. In order to make EAE a balanced metabolite, an exchange reaction describing the draining of EAE is added to the model, with $\Delta G_{\mathrm{EAE}}$ corresponding to the $\Delta G_{\text {red }}$ (kJ/electron-pair) of the specific electron acceptor described in Table 3.

\section{Optimization of $\mathrm{Na}^{+} / \mathrm{H}^{+}$ratios of ATP synthase and Mrp antiporter}

To find the optimal $\mathrm{Na}^{+} / \mathrm{H}^{+}$stoichiometric ratios of ATP synthase and Mrp matching best the observed growth yields, Flux Balance Analysis (FBA) was used as described earlier in this section. FBA optimization problems were solved at varying $\mathrm{Na}^{+} / \mathrm{H}^{+}$ratios of $3: 1,1: 1,1: 3,2: 1$, and 1:2 for ATP synthase and at varying $\mathrm{Na}^{+} / \mathrm{H}^{+}$ratios of $3: 1$, 2:1, 1:1, 1:2, and 1:3 for Mrp. These ratios were selected based on recent findings involving archaeal ATP synthase and their dependence on Mrp. Welte and Deppenmeier [42] estimated that 3-4 translocated ions $\left(\mathrm{H}^{+}\right.$or $\left.\mathrm{Na}^{+}\right)$ are required to synthesize one molecule of ATP based on the measured electrochemical ion gradients available for a limited number of methanogens. Jasso-Chavez 
et al. [40] proposed that Mrp is used for optimization of the thermodynamic efficiency of the ATP synthase in $M$. acetivorans. The objective function was the maximization of cellular growth. This procedure was repeated for both acetate and methanol as sole carbon sources. The sum squared error (SSE) between the predicted and observed growth yields were calculated and results are shown in Table 4 .

\section{Additional files}

Additional file 1. iMAC868 metabolic reconstruction.

Additional file 2. M. acetivorans gene re-annotation.

\section{Abbreviations}

ANME: anaerobic methanotrophic archaea; AOM: anaerobic oxidation of methane; GSM: genome-scale metabolic model; iMAC868: in silico Methanosarcina acetivorans metabolic model containing 868 genes; GPR: gene-proteinreaction associations; R-GPR: regulatory gene-protein-reaction associations; EAE: electron acceptor equivalent.

\section{Author's contributions}

$\mathrm{HN}$-B reconstructed the metabolic network, formulated the LP problems, performed the simulations and analyses, designed and generated the figures and tables, and wrote the manuscript. SG contributed to the reconstruction and analysis of the metabolic network and interpretation of simulation results, participated in designing the figures and tables, and revised the manuscript. JGF provided the data for Additional File 2, contributed to the envisioning and generation of Figure 1, proposed the electron bifurcation mechanism and interpretation of the corresponding simulations results, and contributed in writing of the manuscript. TKW provided insights to the interpretation of the simulation results. CDM supervised and contributed to the design of the study and critically revised the manuscript. All authors read and approved the final manuscript.

\section{Author details}

${ }^{1}$ Department of Chemical Engineering, The Pennsylvania State University, University Park, PA 16802, USA. ${ }^{2}$ Department of Biochemistry and Molecular Biology, The Pennsylvania State University, University Park, PA 16802, USA.

\section{Acknowledgements}

This work was supported by funding from The Advanced Research Projects Agnecy-Energy (ARPA-E), U S Department of Energy to Drs. Costas D. Maranas, Thomas K. Wood, and James G. Ferry, Grant DE-AR0000431. The authors would like to thank Anupam Chowdhury for his useful inputs during the preparation of the manuscript.

\section{Competing interests}

The authors declare that they have no competing interests.

Received: 15 July 2015 Accepted: 22 December 2015

Published online: 17 January 2016

\section{References}

1. Conrad R. The global methane cycle: recent advances in understanding the microbial processes involved. Environ Microbiol Rep. 2009;1:285-92.

2. Wang Q, Chen X, Jha AN, Rogers H. Natural gas from shale formationthe evolution, evidences and challenges of shale gas revolution in United States. Renew Sustain Energy Rev. 2014;30:1-28.

3. McGlade C, Speirs J, Sorrell S. Unconventional gas - a review of regional and global resource estimates. Energy. 2013;55:571-84.

4. Finkel ML, Law A. The rush to drill for natural gas: a public health cautionary tale. Am J Public Health. 2011;101:784-5.
5. Hu D, Xu S. Opportunity, challenges and policy choices for China on the development of shale gas. Energy Policy. 2013;60:21-6.

6. Pierrehumbert RT. Short-lived climate pollution. Annu Rev Earth Planet Sci. 2014;42:341-79.

7. Wegener G, Niemann H, Elvert M, Hinrichs KU, Boetius A. Assimilation of methane and inorganic carbon by microbial communities mediating the anaerobic oxidation of methane. Environ Microbiol. 2008;10:2287-98.

8. Zehnder AJ, Brock TD. Methane formation and methane oxidation by methanogenic bacteria. J Bacteriol. 1979;137:420-32.

9. Hinrichs KU, Hayes JM, Sylva SP, Brewer PG, DeLong EF. Methane-consuming archaebacteria in marine sediments. Nature. 1999;398:802-5.

10. Hoehler TM, Alperin MJ, Albert DB, Martens CS. Field and laboratory studies of methane oxidation in an anoxic marine sediment: evidence for a methanogen-sulfate reducer consortium. Global Biogeochem Cycles. 1994:8:451-63.

11. Knittel K, Boetius A. Anaerobic oxidation of methane: progress with an unknown process. Annu Rev Microbiol. 2009;63:311-34.

12. Thauer RK, Kaster AK, Seedorf H, Buckel W, Hedderich R. Methanogenic archaea: ecologically relevant differences in energy conservation. Nat Rev Microbiol. 2008;6:579-91.

13. Nazaries L, Murrell JC, Millard P, Baggs L, Singh BK. Methane, microbes and models: fundamental understanding of the soil methane cycle for future predictions. Environ Microbiol. 2013;15:2395-417.

14. Conrad R. Soil microorganisms as controllers of atmospheric trace gases (H2, CO, CH4, OCS, N2O, and NO). Microbiol Rev. 1996;60:609-40.

15. Hakemian AS, Rosenzweig AC. The biochemistry of methane oxidation. Annu Rev Biochem. 2007;76:223-41.

16. Lieberman RL, Rosenzweig AC. Biological methane oxidation: regulation, biochemistry, and active site structure of particulate methane monooxygenase. Crit Rev Biochem Mol Biol. 2004;39:147-64.

17. Haynes CA, Gonzalez R. Rethinking biological activation of methane and conversion to liquid fuels. Nat Chem Biol. 2014;10:331-9.

18. Mueller TJ, Grisewood MJ, Nazem-Bokaee H, Gopalakrishnan S, Ferry JG, Wood TK, Maranas CD. Methane oxidation by anaerobic archaea for conversion to liquid fuels. J Ind Microbiol Biotechnol. 2015;42:391-401.

19. Haroon MF, Hu S, Shi Y, Imelfort M, Keller J, Hugenholtz P, Yuan Z, Tyson $\mathrm{GW}$. Anaerobic oxidation of methane coupled to nitrate reduction in a novel archaeal lineage. Nature. 2013;500:567-70.

20. Valentine DL, Reeburgh WS. New perspectives on anaerobic methane oxidation. Environ Microbiol. 2000;2:477-84.

21. Wang FP, Zhang Y, Chen Y, He Y, Qi J, Hinrichs KU, Zhang XX, Xiao X, Boon N. Methanotrophic archaea possessing diverging methane-oxidizing and electron-transporting pathways. ISME J. 2014;8:1069-78.

22. Meyerdierks A, Kube M, Kostadinov I, Teeling H, Glockner FO, Reinhardt R, Amann R. Metagenome and mRNA expression analyses of anaerobic methanotrophic archaea of the ANME-1 group. Environ Microbiol. 2010;12:422-39

23. Moran JJ, House CH, Freeman KH, Ferry JG. Trace methane oxidation studied in several Euryarchaeota under diverse conditions. Archaea. 2005;1:303-9.

24. Moran JJ, House $\mathrm{CH}$, Thomas B, Freeman $\mathrm{KH}$. Products of trace methane oxidation during nonmethyltrophic growth by Methanosarcina. J Geophys Res Biogeosci 2007;112:G02011.

25. Thauer RK. Anaerobic oxidation of methane with sulfate: on the reversibility of the reactions that are catalyzed by enzymes also involved in methanogenesis from $\mathrm{CO}_{2}$. Curr Opin Microbiol. 2011;14:292-9.

26. Thauer RK, Shima S. Methane as fuel for anaerobic microorganisms. Ann NY Acad Sci. 2008;1125:158-70.

27. Galagan JE, Nusbaum C, Roy A, Endrizzi MG, Macdonald P, FitzHugh W, Calvo S, Engels R, Smirnov S, Atnoor D, et al. The genome of M. acetivorans reveals extensive metabolic and physiological diversity. Genome Res. 2002;12:532-42.

28. Kohler PR, MetcalfWW. Genetic manipulation of Methanosarcina spp. Front Microbiol. 2012;3:259.

29. Sowers KR, Baron SF, Ferry JG. Methanosarcina acetivorans sp. nov., an acetotrophic methane-producing bacterium isolated from marine sediments. Appl Environ Microbiol. 1984;47:971-8.

30. Rother M, MetcalfWW. Anaerobic growth of Methanosarcina acetivorans C2A on carbon monoxide: an unusual way of life for a methanogenic archaeon. Proc Natl Acad Sci USA. 2004;101:16929-34. 
31. Li Q, Li L, Rejtar T, Karger BL, Ferry JG. Proteome of Methanosarcina acetivorans Part II: comparison of protein levels in acetate- and methanolgrown cells. J Proteome Res. 2005;4:129-35.

32. Li Q, Li L, Rejtar T, Karger BL, Ferry JG. Proteome of Methanosarcina acetivorans Part I: an expanded view of the biology of the cell. J Proteome Res. 2005;4:112-28.

33. Lessner DJ, Li L, Li Q, Rejtar T, Andreev VP, Reichlen M, Hill K, Moran JJ, Karger BL, Ferry JG. An unconventional pathway for reduction of $\mathrm{CO}_{2}$ to methane in CO-grown Methanosarcina acetivorans revealed by proteomics. Proc Natl Acad Sci USA. 2006;103:17921-6.

34. Li L, Li Q, Rohlin L, Kim U, Salmon K, Rejtar T, Gunsalus RP, Karger BL, Ferry JG. Quantitative proteomic and microarray analysis of the archaeon Methanosarcina acetivorans grown with acetate versus methanol. J Proteome Res. 2007;6:759-71.

35. Satish Kumar V, Ferry JG, Maranas CD. Metabolic reconstruction of the archaeon methanogen Methanosarcina Acetivorans. BMC Syst Biol. 2011;5:28.

36. Benedict MN, Gonnerman MC, MetcalfWW, Price ND. Genome-scale metabolic reconstruction and hypothesis testing in the methanogenic archaeon Methanosarcina acetivorans C2A. J Bacteriol. 2012;194:855-65.

37. Schlegel K, Leone V, Faraldo-Gomez JD, Muller V. Promiscuous archaeal ATP synthase concurrently coupled to $\mathrm{Na}+$ and $\mathrm{H}+$ translocation. Proc Natl Acad Sci USA. 2012;109:947-52.

38. Schlegel K, Welte C, Deppenmeier U, Muller V. Electron transport during aceticlastic methanogenesis by Methanosarcina acetivorans involves a sodium-translocating Rnf complex. FEBS J. 2012;279:4444-52.

39. Schlegel $\mathrm{K}$, Muller $\mathrm{V}$. Evolution of $\mathrm{Na}(+)$ and $\mathrm{H}(+)$ bioenergetics in methanogenic archaea. Biochem Soc Trans. 2013;41:421-6.

40. Jasso-Chavez R, Apolinario EE, Sowers KR, Ferry JG. MrpA functions in energy conversion during acetate-dependent growth of Methanosarcina acetivorans. J Bacteriol. 2013;195:3987-94.

41. Suharti S, Wang M, de Vries S, Ferry JG. Characterization of the RnfB and RnfG subunits of the Rnf complex from the archaeon Methanosarcina acetivorans. PLoS One. 2014;9:e97966.

42. Welte $C$, Deppenmeier U. Bioenergetics and anaerobic respiratory chains of aceticlastic methanogens. Biochim Biophys Acta. 2014;1837:1130-47.

43. Moran JJ, House CH, Vrentas JM, Freeman KH. Methyl sulfide production by a novel carbon monoxide metabolism in Methanosarcina acetivorans. Appl Environ Microbiol. 2008;74:540-2.

44. Wood Tk, Soo V, McAnulty M, Tripathy A, Zhu F, Zhang L, Hatzakis E, Smith P, Agrawal S, Nazem-Bokaee H, et al. Reversing methanogenesis to capture methane for liquid biofuels precursors. Microb Cell Fact. 2015 doi:10.1186/s12934-015-0397-z.

45. Bose A, Pritchett MA, Metcalf WW. Genetic analysis of the methanol- and methylamine-specific methyltransferase 2 genes of Methanosarcina acetivorans C2A. J Bacteriol. 2008;190:4017-26.

46. Guss AM, Mukhopadhyay B, Zhang JK, Metcalf WW. Genetic analysis of mch mutants in two Methanosarcina species demonstrates multiple roles for the methanopterin-dependent C-1 oxidation/reduction pathway and differences in $\mathrm{H}(2)$ metabolism between closely related species. Mol Microbiol. 2005:55:1671-80.

47. Shima S, Krueger M, Weinert T, Demmer U, Kahnt J, Thauer RK, Ermler U. Structure of a methyl-coenzyme M reductase from Black Sea mats that oxidize methane anaerobically. Nature. 2012;481:98-101.

48. Moran JJ, Beal EJ, Vrentas JM, Orphan VJ, Freeman KH, House CH. Methyl sulfides as intermediates in the anaerobic oxidation of methane. Environ Microbiol. 2008;10:162-73.

49. Scheller S, Goenrich M, Boecher R, Thauer RK, Jaun B. The key nickel enzyme of methanogenesis catalyses the anaerobic oxidation of methane. Nature. 2010;465:606-8.

50. Vepachedu VR, Ferry JG. Role of the fused corrinoid/methyl transfer protein $\mathrm{CmtA}$ during $\mathrm{CO}$-dependent growth of Methanosarcina acetivorans. J Bacteriol. 2012;194:4161-8.

51. Terlesky KC, Ferry JG. Ferredoxin requirement for electron transport from the carbon monoxide dehydrogenase complex to a membrane-bound hydrogenase in acetate-grown Methanosarcina thermophila. J Biol Chem. 1988;263:4075-9.

52. Buckel W, Thauer RK. Energy conservation via electron bifurcating ferredoxin reduction and proton/ $\mathrm{Na}(+)$ translocating ferredoxin oxidation. Biochim Biophys Acta. 2013;1827:94-113.
53. Kaster AK, Moll J, Parey K, Thauer RK. Coupling of ferredoxin and heterodisulfide reduction via electron bifurcation in hydrogenotrophic methanogenic archaea. Proc Natl Acad Sci USA. 2011;108:2981-6.

54. Li Q, Li L, Rejtar T, Lessner DJ, Karger BL, Ferry JG. Electron transport in the pathway of acetate conversion to methane in the marine archaeon Methanosarcina acetivorans. J Bacteriol. 2006;188:702-10.

55. Beal EJ, House CH, Orphan VJ. Manganese- and iron-dependent marine methane oxidation. Science. 2009;325:184-7.

56. Lovley DR, Ferry JG. Production and Consumption of H(2) during Growth of Methanosarcina spp. on Acetate. Appl Environ Microbiol. 1985:49:247-9.

57. Lee SK, Chou H, Ham TS, Lee TS, Keasling JD. Metabolic engineering of microorganisms for biofuels production: from bugs to synthetic biology to fuels. Curr Opin Biotechnol. 2008;19:556-63.

58. Atsumi S, Cann AF, Connor MR, Shen CR, Smith KM, Brynildsen MP, Chou KJ, Hanai T, Liao JC. Metabolic engineering of Escherichia coli for 1-butanol production. Metab Eng. 2008;10:305-11.

59. Atsumi S, Li Z, Liao JC. Acetolactate synthase from Bacillus subtilis serves as a 2-ketoisovalerate decarboxylase for isobutanol biosynthesis in Escherichia coli. Appl Environ Microbiol. 2009;75:6306-11.

60. Chindelevitch L, Trigg J, Regev A, Berger B. An exact arithmetic toolbox for a consistent and reproducible structural analysis of metabolic network models. Nat Commun. 2014;5:4893.

61. Orth JD, Thiele I, Palsson BO. What is flux balance analysis? Nat Biotechnol. 2010;28:245-8.

62. Schellenberger J, Que R, Fleming RM, Thiele I, Orth JD, Feist AM, Zielinski DC, Bordbar A, Lewis NE, Rahmanian S, et al. Quantitative prediction of cellular metabolism with constraint-based models: the COBRA Toolbox v2.0. Nat Protoc. 2011;6:1290-307.

63. Mahadevan $\mathrm{R}$, Schilling $\mathrm{CH}$. The effects of alternate optimal solutions in constraint-based genome-scale metabolic models. Metab Eng. 2003;5:264-76.

64. Alberty RA. Calculation of standard transformed Gibbs energies and standard transformed enthalpies of biochemical reactants. Arch Biochem Biophys. 1998:353:116-30.

65. Ogata H, Goto S, Sato K, Fujibuchi W, Bono H, Kanehisa M. KEGG: Kyoto Encyclopedia of genes and genomes. Nucleic Acids Res. 1999;27:29-34

66. Caspi R, Altman T, Dreher K, Fulcher CA, Subhraveti P, Keseler IM, Kothari A, Krummenacker M, Latendresse M, Mueller LA, et al. The MetaCyc database of metabolic pathways and enzymes and the BioCyc collection of pathway/genome databases. Nucleic Acids Res. 2012;40:D742-53.

67. Schomburg I, Chang A, Placzek S, Sohngen C, Rother M, Lang M, Munaretto C, Ulas S, Stelzer M, Grote A, et al. BRENDA in 2013: integrated reactions, kinetic data, enzyme function data, improved disease classification: new options and contents in BRENDA. Nucleic Acids Res. 2013:41:D764-72.

68. Ren Q, Chen K, Paulsen IT. TransportDB: a comprehensive database resource for cytoplasmic membrane transport systems and outer membrane channels. Nucleic Acids Res. 2007;35:D274-9.

69. Summer H. Improved approach for transferring and cultivating Methanosarcina acetivorans C2A (DSM 2834). Lett Appl Microbiol. 2009;48:786-9.

70. Buan NR, MetcalfWW. Methanogenesis by Methanosarcina acetivorans involves two structurally and functionally distinct classes of heterodisulfide reductase. Mol Microbiol. 2010;75:843-53.

71. Oelgeschlager $\mathrm{E}$, Rother $\mathrm{M}$. In vivo role of three fused corrinoid/ methyl transfer proteins in Methanosarcina acetivorans. Mol Microbiol. 2009;72:1260-72.

72. Mahapatra A, Srinivasan G, Richter KB, Meyer A, Lienard T, Zhang JK, Zhao G, Kang PT, Chan M, Gottschalk G, et al. Class I and class II lysyl-tRNA synthetase mutants and the genetic encoding of pyrrolysine in Methanosarcina spp. Mol Microbiol. 2007;64:1306-18.

73. Rother M, Boccazzi P, Bose A, Pritchett MA, MetcalfWW. Methanoldependent gene expression demonstrates that methyl-coenzyme M reductase is essential in Methanosarcina acetivorans C2A and allows isolation of mutants with defects in regulation of the methanol utilization pathway. J Bacteriol. 2005;187:5552-9. 